\title{
Platelet-rich plasma (PRP) therapy: An approach in reproductive medicine based on successful animal models
}

\author{
Natalia Juliana Nardelli Gonçalves ${ }^{\S}$, Nilo Frantz, Ricardo Manuel de Oliveira
}

RDO Medical Diagnosis, São Paulo, Brazil.

\begin{abstract}
Platelet-rich plasma (PRP) has been fully studied for different clinical applications in veterinary medicine for many years with promising results. As a result, therapeutic studies to elucidate pathways for PRP use in human reproduction have been performed. PRP applications in human reproductive medicine are recent, but the role of platelet growth factors in improving the endometrial environment is well known. Indications for PRP therapy show its positive effects in promoting endometrial and follicular growth and gestation in assisted reproduction cycles, as has been proven in animals. We summarized the putative role of PRP on endometrial receptivity with a brief history of promising results in research and clinical therapies.
\end{abstract}

Keywords: Platelet-rich plasma, reproduction, uterine environment, infertility.

\section{Introduction}

Platelets play an important role in hemostasis by preventing blood loss at sites of vascular injury. The physiologic process begins with the adherence and aggregation of platelets that then forms a procoagulant surface, leading to thrombin generation and fibrin formation. Platelets also release substances that promote tissue repair and influence the reactivity of vascular and other blood cells in angiogenesis and inflammation. They contain important growth factors, such as PDGF (platelet-derived growth factor), TGF- $\beta$ (transformer growth factor- $\beta$ ), and VEGF (vascular endothelial growth factor), as well as the cytokines PF4 (platelet factor 4) and CD40L (Sills et al., 2018; Anitua et al., 2004). These growth factors and cytokines are critical in the activation of fibroblasts and the recruitment of leukocytes to the injury site, inducing and regulating the proliferation and migration of other cell types involved in tissue repair. In addition, platelet-derived factors are essential for endometrial progenitor cell activity (Gargett et al., 2008), and PDGF isoforms significantly promote endometrial stromal cell proliferation, migration, and contractility (Matsumoto et al., 2005; Aghajanova et al., 2018).

Platelet-rich plasma (PRP) has been recently applied in reproductive scenarios and is based on the knowledge that platelet growth factors can improve the endometrial environment, which is full of growth-factor receptors, adhesion molecules, cytokines, lipids, and other factors that enhance endometrial and embryonic development. Despite the progress in the field of assisted reproductive technology, multiple embryos fail to implant.

PRP contains growth factors and other cytokines that have positive effects on local tissue repair and endometrial receptivity (Farimani et al., 2017). A significant percentage of in vitro fertilization failure is due to poor endometrial receptivity; implantation requires good embryo quality to provide a good coordination between mother and fetus. The human endometrium undergoes significant changes during implantation, and immune cells and their secreted substances in the luteal phase, such as granulocyte colony-stimulating factor (G-CSF), play an important role in this process (Farimani et al., 2017; Aghajanova et al., 2018).

In this context, the influence of platelet growth factors on the relationship between the uterine environment and embryo implantation has been widely studied, and the results are encouraging. We summarize the most relevant clinical findings in both animal models and clinical trials that led to the recognition of PRP as an important ally in reproductive medicine.

\section{Platelet-rich plasma (PRP): a source of growth factors}

PRP is easy to obtain, low cost, and rich in growth factors. Since PRP is an autologous preparation, and therefore non-toxic and non-allergenic, it can be used in various medical conditions as an adjuvant therapy to conventional treatment, with generally satisfactory results (Molina et al., 2018).

The use of autologous PRP in clinical research has grown exponentially over recent years due to the increasing understanding of the role PRP's growth factors play in tissue regeneration (Scully et al., 2018). The history of PRP began with the first publication in Nature magazine (Kingsley, 1954), followed around ten years later by the first article to describe applying PRP in a therapeutic approach (Levin et al., 1964). As a result, PRP became an attractive methodology in several therapeutic areas.

New protocols, with the principal goal to improve the process and purity of PRP, are frequently published. Gutierrez et al. (2017) reported a two-step centrifugation protocol for concentrating cells and growth factors in bovine PRP. Figure 1 exemplifies the methodological basis for obtaining PRP and its many applications. Each preparation method is intended to create a product with a particular bioaction and, consequently, with a specific clinical application. Thus, PRP is not considered to be a single, final blood derivate containing plasma and high concentrations of platelets (Bos-Mikich et al., 2018). 

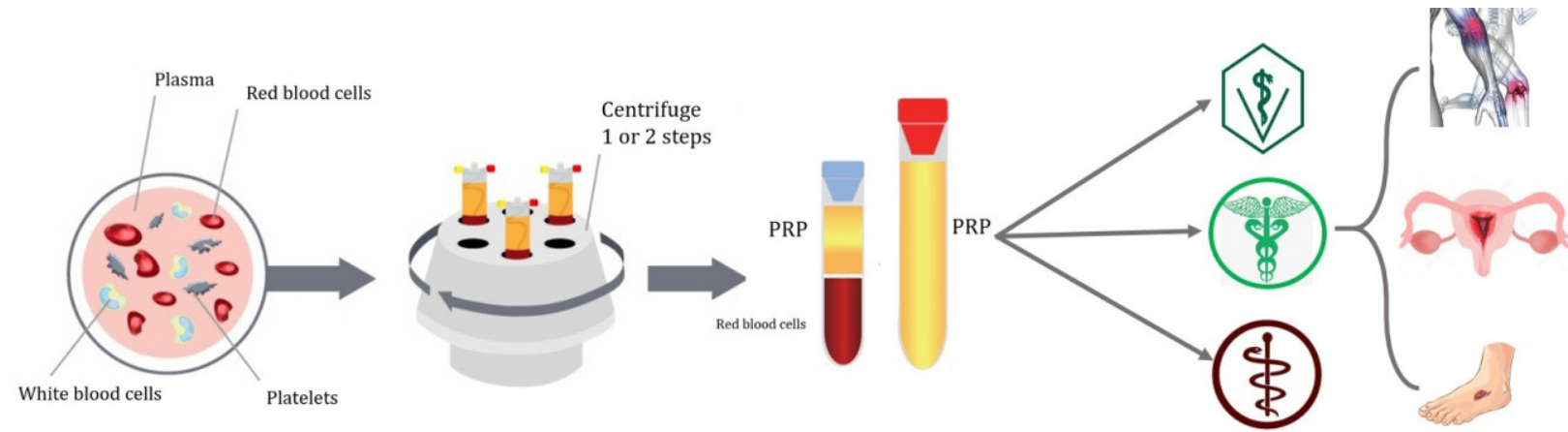

Figure 1. Illustration of platelet-rich plasma (PRP) protocol. Obtaining PRP involves the drawing of a small volume of blood from the patient, a centrifugation step to fractionate the blood, and the separation of platelet-rich fractions. Various formulations, including liquid clot and membrane, can be obtained for use in many applications, including veterinary medicine, human medicine, and odontology. In humans, PRP can be used especially in orthopedic issues, reproduction, and dermatological ulcerations.

There are four classifications of platelet concentrates that depend on their leucocyte and fibrin content: pure platelet-rich plasma (P-PRP), leucocyteand platelet-rich plasma (LPRP), pure platelet-rich fibrin (P-PRF), and leucocyte- and platelet-rich fibrin (L-PRF) (Ehrenfest et al., 2009; Gutierrez et al., 2017).

Bos-Mikich et al. (2018) described PRP as the volume of plasma that has a platelet count above the baseline. PRP was later defined as a group of soluble and diffusible polypeptide substances able to regulate the growth, differentiation, and phenotype of numerous cell types (Bos-Mikich et al., 2018). Platelets are small and anucleated cell fragments ( 2 to $3 \mu \mathrm{m}$ in diameter) released from megakaryocytes found in the bone marrow (Pietrzak et al., 2005).
We summarized the effects of PRP growth factors in Table 1, and the main ones are as follows: (1) PRP growth factors are capable of acting in a paracrine way on different cell types, such as myocytes, mesenchymal stem cells, chondrocytes, osteoblasts, and fibroblasts (Graziani et al., 2005; Anitua et al., 2009; Drengk et al., 2009; Cho et al., 2011; Van et al., 2011; Mazzocca et al., 2012); (2) PRP growth factors increase the infiltration of neutrophils and macrophages that promote angiogenesis, fibroplasia, and matrix deposition, which induce the consequent tissue regeneration; (3) and PRP growth factors have anti-inflammatory properties (Anitua et al., 2004; Bendinelli et al., 2010; LangeConsiglio et al., 2015).

Table 1. Growth factors secreted by platelets and their main functions.

\begin{tabular}{|c|c|}
\hline TGF- $\beta$ - transforming growth factor beta & PGDFa-b - platelet-derived growth factor \\
\hline Undifferentiated mesenchymal cells prolifieration & Mitogenic effect for mesenchymal cells and osteoblasts \\
\hline Regulates endothelial, fibroblastic, and osteoblastic mitogenesis & Mitogenesis/chemotaxis in fibroblasts and smooth muscle cells \\
\hline Regulation of synthesis and secretion of collagen & Regulates collagenase secretion and collagen synthesis \\
\hline Regulates the mitogenic effect of other growth factors & Chemotaxis of neutrophils and macrophages \\
\hline \multirow{2}{*}{\multicolumn{2}{|c|}{$\begin{array}{l}\text { Chemotaxis and endothelial angiogenesis } \\
\text { Inhibits proliferation of lymphocytes and macrophages }\end{array}$}} \\
\hline & \\
\hline EGF- Epidermal growth factor & VEGF- Vascular endothelial growth factor \\
\hline Angiogenesis and endothelial chemotaxis & Increases angiogenesis and vascular permeability \\
\hline Regulates collagenase secretion & Stimulates mitogenesis to endothelial cells \\
\hline Epithelial and mesenchymal mitogenesis & \\
\hline bFGF- Basic fibroblast growth factor & CTGF - Connective tissue growth factor \\
\hline Growth and differentiation of chondrocytes and osteoblasts & Angiogenesis and regeneration of cartilage \\
\hline Mitogenic factor for mesenchymal cells, chondrocytes, and o & Fibrosis and platelet aggregation \\
\hline
\end{tabular}

\section{PRP and successful animal models}

PRP has been studied for several clinical applications in veterinary medicine with promising results, and this has encouraged therapeutic studies to elucidate the pathways for its use in human reproduction. Examples include using PRP in horses for orthopedic therapy (musculoskeletal lesions) and tenodesmic lesions (Scala et al., 2014; Brossi et al., 2015), and using PRP in dogs for orthopedic therapy of ligament rupture by intra-articular injections (Silva et al., 2013; Vilar et al., 2013). Groups of veterinary researchers have studied the biology of PRP more extensively (mostly cellular and molecular studies) in horses (Rinnovati et al., 2016; Giraldo et al., 2015; Hessel et al., 2015; Hauschild et al., 2017) than in dogs (Silva et al., 2012; Carr et al., 2016; Frye et al., 2016).

Scully et al. (2018) reviewed the PRP applications in animal models for regenerative tissue, and they reported some important observations in rats (Hammond et al., 2009, Borrione et al., 2014; Martins et al., 2016; Li et al., 2016; Pinheiro et al., 2016; Borrione et al., 2017) using the application of PRP on a flexor sublimis lesion and tibialis anterior under muscle strain. The results showed a significant improvement in leukocyte infiltration, inflammatory response, the increase of pro-inflammatory cytokines, and myogenesis. Other studies of mouse and rat models 
using PRP reported an increase in cell proliferation, proinflammatory cytokines, and muscle regeneration (Notodihardjo et al., 2015; Denapoli et al., 2016).

Larson et al. (1992) successfully developed bovine embryos during the fourth cell cycle after using PRP. That study (1992) corroborates with new findings (Farimani et al., 2016) that demonstrate the PRP method reduces abortion rates by increasing endometrial thickness.

In 2014, the first clinical application of PRP for mastitis using intramammary administration was reported, and the authors concluded that PRP might be useful for a quick resolution of the inflammatory response by playing a role in limiting the tissue damage of the mammary gland parenchyma and reducing the recurrence rates (Lange-Consiglio et al., 2014). In 2015, Lange-Consiglio and colleagues focused on reproductive problems by evaluating the effects of intrauterine administration of PRP on in vitro embryo production, with encouraging results.

Marini et al. (2016) evaluated the effect of PRP in vitro for bovine endometrial inflammation and obtained an important anti-inflammatory response in the evaluated cells, concluding that PRP should be considered a potential treatment for endometritis in vivo. Endometritis is characterized by an increased number of inflammatory cells associated with epithelial erosion and/or necrosis, and diffuse oedema of the endometrium. In most cases, the normal uterus is able to clear a bacterial infection efficiently. However, an uncontrolled infection (10\%-20\% of cows) may lead to chronic uterine inflammation.

Meta-analysis studies showed that endometritis reduces the pregnancy rate by $16 \%$ (Fourichon et al., 2000), and the economic losses related to this disease are substantial (Sheldon et al., 2009).

Jang et al. (2017) investigated PRP treatment for damaged endometrium, and the research group concluded that the intrauterine administration of autologous PRP stimulated and accelerated regeneration of the endometrium and decreased fibrosis in a murine model.

With these animal model studies, we can conclude that PRP enriches the uterine environment with the growth factors necessary for embryo development and counteracts eventual subclinical endometritis by its anti-inflammatory properties.

\section{PRP and human reproduction}

Since the first in vitro fertilization (IVF) attempts in the mid-1970s, researchers have been aware of the important role played by the endometrium, in addition to the embryo itself, in achieving a pregnancy (Bos-Mikich et al., 2018). Czernobilsky (1978) published a paper emphasizing the importance of the diagnosis of endometritis and its consequences on a woman's fertility.

Koot et al. (2011) attributed a successful implantation to a receptive endometrium, a functional embryo at the blastocyst developmental stage, and a synchronized dialogue between the maternal and embryonic tissues, in a perfect endometrial-embryo relationship. Recurrent implantation failures can be attributed to many factors, with one of the most important being a refractory endometrium, which is characterized by measurements below $6 \mathrm{~mm}$ and the presence of intrauterine adhesions (detected by a hysteroscopy). The causes can be idiopathic, congenital, or surgical (curettage), or by many inflammatory processes, infections, radiations, and other reasons (Coughlan et al., 2014; Kasius et al., 2014).

The standard protocol for preparing infertile women's endometria are hormone therapies. However, because of the complexity of causes, other therapies may be considered to ensure adequate synchronization. Recently, alternative treatment modalities have been explored, including growth factors (mainly G-CSF), stem cells, PRP, and bone marrow (Ohl et al., 2002; Barad et al., 2014; Kunicki et al., 2014; Singh et al., 2014; Chang et al., 2015).

A proportion of women has 'unexplained' infertility, in which pregnancies fail before they are clinically recognized. Garcia-Velasco et al. (2016) performed an extensive literature review on the management of refractory endometrium using conventional hormone protocols and autologous preparations as growth factors, such as PRP, and showed that the uterine environment is a protagonist in the process of embryonic failure.

In 2015, Chang et al. performed a first clinical trial using PRP to improve endometrial thickness in patients undergoing IVF treatment. Five patients, with poor endometrial response after standard hormone replacement therapy, received an intrauterine infusion of PRP, 1-2 times in each cycle. The endometrial thickness increased, and four patients had a successful pregnancy, which proved PRP's ability to improve pregnancy outcomes. Since then, some clinical studies and several reviews have explored the subject and concluded that intrauterine PRP therapy is promising, and the results are extremely encouraging.

Farimani et al. (2016) performed a single-blind pilot study to support the hypothesis that intrauterine administration of PRP could improve pregnancy outcomes of frozen-thawed embryo transfer. Nine patients with a history of recurrent implantation failure were selected for the study, and six women achieved clinical pregnancy (pregnancy rate was $66.6 \%$ ). In 2017 , Farimani reported a successful case of a 45 year-old woman with primary infertility and two failed IVF cycles. The patient was treated with intrauterine administration of autologous PRP to improve endometrial receptivity, and the patient became pregnant and had a term gestation, showing the effectiveness of PRP.

Zadehmodarres et al. (2017) in a pilot study recruited ten patients with a history of inadequate endometrial growth in frozen-thawed embryo transfer cycles. Intrauterine PRP infusion was successful for endometrial growth (adequate endometrial growth was found in all the participants after two PRP infusions).

Molina et al. (2018) also performed a clinical trial using PRP to increase endometrial quality and implantation rates in patients with refractory 
endometrium. Nineteen patients received an intrauterine infusion, and $73.7 \%$ became pregnant. The authors concluded that, despite the vast array of resources available today, it is still not easy to provide a pragmatic evidence-based approach that guides the clinician on how to improve refractory endometrium.

\section{Conclusions}

PRP represents a novel strategy for reproductive medicine with clinical issues, such as thin endometrium (with poor response to conven tional therapy), as well as to obtain positive clinical pregnancies and live births. Being an autologous resource, PRP is harmless to the patient, easy to obtain, and of very low cost. Therefore, this protocol should be included for endometrial preparation in assisted reproduction techniques. However, more randomized, controlled trials with large sample sizes are necessary in this field. These studies and basic research on the cellular and molecular levels can improve our knowledge on PRP's mode of action to better understand how and in what clinical situations it should be administered.

\section{References}

Aghajanova L, Houshdaran S, Balayan S, Manvelyan S, Irwin JC, Huddleston HG, Giudice LC. 2018. In vitro evidence that platelet-rich plasma stimulates cellular processes involved in endometrial regeneration. J Assist Reprod Genet, 35:757-770.

Anitua E, Andia I, Ardanza B, Nurden P, Nurden AT. 2004. Autologous platelets as a source of proteins for healing and tissue regeneration. Thromb Haemost, 91:4-15.

Anitua E, Sánchez M, Del Mar ZM, De La Fuente M, Prado R, Orive G. 2009. Fibroblastic response to treatment with different preparations rich in growth factors. Cell Prolif, 42:162-170.

Barad DH, Yu Y, Kushnir VA, Shohat-Tal A, Lazzaroni E, Lee HJ, Gleicher N. 2014. A randomized clinical trial of endometrial perfusion with granulocyte colony-stimulating factor in in vitro fertilization cycles: impact on endometrial thickness and clinical pregnancy rates. Fertil Steril, 101:710-705.

Bendinelli P, Matteucci E, Dogliotti G, Corsi MM, Banfi G, Maroni P. 2010. Molecular basis of antiinflammatory action of platelet rich plasma on human chondrocytes: mechanisms of NF-kB inhibition via HGF. J Cell Physiol, 225:757-766.

Borrione P, Grasso L, Chierto E, Geuna S, Racca S, Abbadessa G, Ronchi G, Faiola F, Di Gianfrancesco A, Pigozzi F. 2014. Experimental model for the study of the effects of platelet-rich plasma on the early phases of muscle healing. Blood Transfus, 12:s221-s8.

Borrione P, Fagnani F, Di Gianfrancesco A, Mancini A, Pigozzi F, Pitsiladis Y. 2017. The role of plateletrich plasma in muscle healing. Curr Sports Med Rep, 16:459-463.

Brossi PM, Moreira JJ, Machado TS, Baccarin RY 2015. Platelet-rich plasma in orthopedic therapy: a comparative systematic review of clinical and experimental data in equine and human musculoskeletal lesions. BMC Vet Res, 11:98-148.

Bos-Mikich A, Oliveira RM, Frantz N. 2018. Plateletrich plasma therapy and reproductive medicine. J Assist Reprod Genet, 35:753-756.

Carr BJ, Canapp SO, Mason DR, Cox C, Hess T. 2016. Canine platelet-rich plasma systems: a prospective analysis. Front Vet Sci, 2:73.

Chang Y, Li J, Chen Y, Wei L, Yang X, Shi Y, Liang X. 2015. Autologous platelet-rich plasma promotes endometrial growth and improves pregnancy outcome during in vitro fertilization. Int J Clin Exp Med, 8:1286-90. Cho HS, Song LH, Park SY, Sung MC, Ahn MW, Song KE. 2011. Individual variation in growth factor concentrations in platelet-rich plasma and its influence on human mesenchymal stem cells. Korean J Lab Med, 31:212-218.

Coughlan C, Ledger W, Wang Q, Liu F, Demirol A, Gurgan T, Cutting R, Ong K, Sallam H, Li TC. 2014. Recurrent implantation failure: definition and management. Reprod Biomed Online, 28:14-38.

Denapoli PM, Stilhano RS, Ingham SJ, Han SW, Abdalla RJ. 2016. Platelet-rich plasma in a murine model: leukocytes, growth factors, Flt-1, and muscle healing. Am J Sports Med, 44:1962-1971.

Dimauro I, Grasso L, Fittipaldi S, Fantini C, Mercatelli N, Racca S, Geuna S, Di Gianfrancesco A, Caporossi D, Pigozzi F, Borrione P. 2014. Plateletrich plasma and skeletal muscle healing: a molecular analysis of the early phases of the regeneration process in an experimental animal model. Plos One, 9:e102993.

Drengk A, Zapf A, Stürmer EK, Stürmer KM, Frosch KH. 2009. Influence of platelet-rich plasma on chondrogenic differentiation and proliferation of chondrocytes and mesenchymal stem cells. Cells Tissues Organs, 189:317-326.

Ehrenfest DM, Rasmusson L, Albrektsson T. 2009. Classification of platelet concentrates: from pure platelet-rich plasma (P-PRP) to leucocyte- and plateletrich fibrin (L-PRF). Trends Biotechnol, 27:158-167.

Farimani M, Bahmanzadeh M, Poorolajal J. 2016. A new approach using autologous platelet-rich plasma to treat infertility and to improve population replacement rate. J Res Health Sci, 16:172-173.

Farimani M, Poorolajal J, Rabiee S, Bahmanzadeh M. 2017. Successful pregnancy and live birth after intrauterine administration of autologous platelet-rich plasma in a woman with recurrent implantation failure: A case report. Int J Reprod BioMed, 15:803-806.

Fourichon C, Seegers H, Malher X. 2000. Effect of disease on reproduction in the dairy cow: a metaanalysis. Theriogenology, 53:1729-1759.

Frye CW, Enders A, Brooks MB, Struble AM, Wakshlag JJ. 2016. Assessment of canine autologous platelet-rich plasma produced with a commercial centrifugation and platelet recovery kit. Vet Comp Orthop Traumatol, 29:14-19.

Gargett CE, Chan RW, Schwab KE. 2008. Hormone and growth factor signaling in endometrial renewal: role of stem/progenitor cells. Mol Cell Endocrinol, 288:2229 
Giraldo CE, Alvarez ME, Carmona JU. 2015. Effects of sodium citrate and acid citrate dextrose solutions on cell counts and growth factor release from equine pureplatelet rich plasma and pure-platelet rich gel. BMC Vet Res, 11:60.

Graziani F, Ivanovski S, Cei S, Ducci F, Tonetti M, Gabriele M. 2005. The in vitro effect of different concentrations on osteoblasts and fibroblasts. Clin Oral Implants Res, 16:456-460.

Gutiérrez CM, López C, Giraldo CE, Carmona JU. 2017. Study of a two-step centrifugation protocol for concentrating cells and growth factors in bovine platelet-rich plasma. Vet Med Int, 2017:1-8.

Hammond JW, Hinton RY, Curl LA, Muriel JM, Lovering RM. 2009. Use of autologous platelet-rich plasma to treat muscle strain injuries. Am J Sports Med, 37:1135-1142.

Hauschild G, Geburek F, Gosheger G. 2017. Short term storage stability at room temperature of two different platelet-rich plasma preparations from equine donors and potential impact on growth factor concentrations. BMC Vet Res, 13:7.

Hessel LN, Bosch G, Weeren PR, Ionita JC. 2015. Equine autologous platelet concentrates: a comparative study between different available systems. Equine Vet $J$, 47:319-325.

Jang HY, Myoung SM, Choe JM, Kim T, Cheon YP, Kim YM, Park H. 2017. Effects of autologous plateletrich plasma on regeneration of damaged endometrium in female rats. Yonsei Med J, 58:1195-1203.

Kasius A, Smit JG, Torrance HL, Eijkemans MJ, Mol BW, Opmeer BC, Broekmans FJ. 2014. Endometrial thickness and pregnancy rates after IVF: a systematic review and meta-analysis. Hum Reprod Update, 20:530-541.

Kingsley CS. 1954. Blood coagulation; evidence of an antagonist to factor VI in platelet-rich human plasma. Nature, 173:723-724.

Koot YE, Boomsma CM, Eijkemans MJ, Lentjes EG, Macklon NS. 2011. Recurrent pre-clinical pregnancy loss is unlikely to be a 'cause' of unexplained infertility. Hum Reprod, 26:2636-2641.

Kunicki M, Lukaszuk K, Woclawek-Potocka I, Liss J, Kulwikowska P, Szczyptańska J. 2014. Evaluation of granulocyte colony-stimulating factor effects on treatment-resistant thin endometrium in women undergoing in vitro fertilization. Biomed Res Int, 2014:1-5.

Lange-Consiglio A, Cazzaniga N, Garlappi R, Spelta C, Pollera C, Perrini C, Cremonesi, F. 2015. Platelet concentrate in bovine reproduction: effects on in vitro embryo production and after intrauterine administration in repeat breeder cows. Reprod Biol Endocrin, 13:65.

Lange-Consiglio A, Spelta C, Garlappi R, Luini M, Cremonesi F. 2014. Intramammary administration of platelet concentrate as an unconventional therapy in bovine mastitis: first clinical application. J Dairy $S c i$, 97:6223-6230.

Larson R, Ignotz G, Currie W. 1992. Platelet derived growth factor (PDGF) stimulates development of bovine embryos during the fourth cell cycle. Development, 115:821-826.
Levin RH, Freireich EJ. 1964. Effect of storage up to 48 hours on response to transfusions of platelet rich plasma. Transfusion, 4:251-256.

Li H, Hicks JJ, Wang L, Oyster N, Philippon MJ, Hurwitz S, Hogan MV, Huard J. 2016. Customized platelet-rich plasma with transforming growth factor beta1 neutralization antibody to reduce fibrosis in skeletal muscle. Biomaterials, 87:147-156.

Marini MG, Perrini C, Esposti P, Corradetti B, Bizzaro D, Riccaboni P, Fantinato E, Urbani G, Gelati G, Cremonesi F, Lange-Consiglio A. 2016. Effects of platelet-rich plasma in a model of bovine endometrial inflammation in vitro. Reprod Biol Endocrin, 14:1-17.

Martins RP, Hartmann DD, de Moraes JP, Soares FA, Puntel GO. 2016. Platelet-rich plasma reduces the oxidative damage determined by a skeletal muscle contusion in rats. Platelets, 27:784-790.

Matsumoto $H$, Nasu $K$, Nishida $M$, Ito $H$, Bing $S$, Miyakawa I. 2005. Regulation of proliferation, motility, and contractility of human endometrial stromal cells by platelet-derived growth factor. $J$ Clin Endocrinol Metab, 90:3560-3567.

Mazzocca AD, McCarthy MB, Chowaniec DM, Dugdale EM, Hansen D, Cote MP. 2012. The positive effects of different platelet-rich plasma methods on human muscle, bone, and tendon cells. Am J Sports Med, 40:1742-1749.

Molina A, Sánchez J, Sánchez W, Vielma W. 2018. Platelet-rich plasma as an adjuvant in the endometrial preparation of patients with refractory endometrium. JBRA Assisted Reproduction, 22:42-48.

Notodihardjo PV, Morimoto N, Kakudo N, Kakudo N, Matsui M, Sakamoto M, Liem PH, Suzuki K, Tabata Y, Kusumoto K. 2015. Gelatin hydrogel impregnated with platelet-rich plasma releasate promotes angiogenesis and wound healing in murine model. J Artif Organs, 18:64-71.

Ohl J, Lefèbvre-Maunoury C, Wittemer C, Nisand G, Laurent MC, Hoffmann P. 2002. Nitric oxide donors for patients undergoing IVF. A prospective, double-blind, randomized, placebo-controlled trial. Hum Reprod, 17:2615-2620.

Pinheiro CL, Peixinho CC, Esposito CC, Manso JE, Machado JC. 2016. Ultrasound biomicroscopy and claudication test for in vivo follow-up of muscle repair enhancement based on platelet-rich plasma therapy in a rat model of gastrocnemius laceration. Acta Cir Bras, 31:103-110.

Rinnovati R, Romagnoli N, Gentilini F, Lambertini C, Spadari A. 2016. The influence of environmental variables on platelet concentration in horse platelet-rich plasma. Acta Vet Scand, 58:45.

Scala M, Lenarduzzi S, Spagnolo F. 2014. Regenerative medicine for the treatment of Teno-desmic injuries of the equine. A series of 150 horses treated with platelet-derived growth factors. In Vivo, 6:111911124

Scully D, Naseem KM, Matsakas A. 2018. Platelet biology in regenerative medicine of skeletal muscle. Acta Physyol, 223:e13071.

Sheldon IM, Cronin J, Goetze L, Donofrio G, Schub 
HJ. 2009. Defining postpartum uterine disease and the mechanisms of infection and immunity in the female reproductive tract in Cattle. Reprod Biol Endocrinol, 81:1025-1032.

Sills SE, Rickers NS, Li X, Palermo GD. 2018. First data on in vitro fertilization and blastocyst formation after intraovarian injection of calcium gluconateactivated autologous platelet rich plasma. Gynecol Endocrinol, 28:1-5.

Silva RF, Carmona JU, Rezende CM. 2013. Intraarticular injections of autologous platelet concentrates in dogs with surgical reparation of cranial cruciate ligament rupture. Vet Comp Orthop Traumatol, 26:285290.

Silva RF, Carmona JU, Rezende CM. 2012. Comparison of the effect of calcium gluconate and batroxobin on the release of transforming growth factor beta 1 in canine platelet concentrates. BMC Vet Res, $8: 121$.
Singh N, Mohanty S, Seth T, Shankar M, Bhaskaran S, Dharmendra S. 2014. Autologous stem cell transplantation in refractory Asherman's syndrome: A novel cell based therapy. J Hum Reprod Sci, 7:93-98.

Velasco JA, Acevedo B, Alvarez C, Alvarez M, Bellver J, Fontes J, Landeras J, Manau D, Martinez F, Muñoz E, Robles A, Rodriguez-Tabernero L. 2016. Strategies to manage refractory endometrium: state of the art in 2016. Reprod BioMed Online, 32:474489.

Vilar JM, Morales M, Santana A. 2013. Controlled, blinded force platformanalysis of the effect of intraarticular injection of autologous adipose-derived mesenchymal stem cells associated to PRGF-Endoret in osteoarthritic dogs. BMC Vet Res, 9:131.

Zadehmodarres S, Salehpour S, Saharkhiz N, Nazari L. 2017. Treatment of thin endometrium with autologous platelet-rich plasma: a pilot study. JBRA Assisted Reproduction, 21:54-56. 